\title{
COMPARISON OF CUTOFF POINTS OF SKELETAL MASS INDEX AND THEIR CORRELATION WITH AGE
}

Cristiane Junqueira Carvalho (Universidade Federal de Viçosa, Viçosa, MG, Brasil), Giana Zarbato Longo (Universidade Federal de Viçosa, Viçosa, MG, Brasil), Adriana Maria Kakehasi (Universidade Federal de Minas Gerais, Belo Horizonte, MG, Brasil), Leidjaira Juvanhol Lopes (Universidade Federal de Viçosa, Viçosa, MG, Brasil), Andréia Queiroz Ribeiro (Universidade Federal de Viçosa, Viçosa, MG, Brasil)

\section{BACKGROUND}

Muscle mass has been studied using body composition indices, but few Brazilian population-based studies aimed at producing cutoff values for such indices, especially among adults. to establish cutoff values for measures and indices of body composition by age and sex, compare them with data from other ethnic groups and evaluate their correlation with age. The purpose of this study was to establish cutoff values for measures and indices of body composition by age and sex, compare them with data from other ethnic groups and evaluate their correlation with age.

\section{MATERIALS AND METHODS}

Cross-sectional, population-based study with adults aged 20-59 years ( $n=689)$. Skeletal mass index (SMI), fat mass index (FMI), body fat (BF), and load-capacity metabolic indices (LCMI) were assessed from dualenergy X-ray absorptiometry (DXA).

\section{RESULTS}

Cut-off points for SMI were generated in 204 men and 221 women between 20 and 39 years. Our cut-off points were lower than those proposed by the other presented studies, except for the SMlheight value proposed by a study carried out in the Korean population. The values found for SMlheight were 6.34 $\mathrm{kg} / \mathrm{m} 2$ and $4.45 \mathrm{~kg} / \mathrm{m} 2$, for SMIBMI $0.74 \mathrm{~kg} / \mathrm{kg} / \mathrm{m} 2$ and $0.49 \mathrm{~kg} / \mathrm{kg} / \mathrm{m} 2$, and for SMIweight $29.84 \%$ and $23.15 \%$, respectively, for men and women. The parameters evaluated showed a significant correlation with age. Correlation coefficients were similar between men and women. SMIweight and SMIBMI presented a negative correlation $(-0.263$ and -0.382 in males and -0.364 and -0.471 in females, respectively) and the other indices correlated positively with age (FMI: 0.265 and 0.334 , BF: 0.228 and 0.293, LCMItotal0.222 and 0.264, LCMIregional: 0.330 and 0.389, SMIheight: 0.120 and 0.237 in men and women, respectively).

\section{CONCLUSION}

Pearson correlation coefficients in both sexes revealed significant associations between the indices studied and age and the comparison of the SMI cutoff points indicated the low cut-off point of our sample in the three skeletal mass indices studied, which may be related to the high prevalence of leisure-time physical inactivity in the sample. 